\title{
Curious case of Retrosternal Colloid Goitre
}

Prathamesh $\mathbf{P}^{1}$, Raviraj $C^{1}$, Chatterjee $S^{* 2}$

${ }^{1}$ MBBS, General surgery resident at Bombay Hospital, India.

${ }^{2}$ Assistant Professor, Maharashtra University of health sciences, Nashik, Postgraduate Teacher, Bombay hospital Institute of Medical Sciences, General surgery resident at Bombay Hospital, India.

*Corresponding Author: Chatterjee S, Assistant Professor, Maharashtra University of health sciences, Nashik, Postgraduate Teacher, Bombay hospital Institute of Medical Sciences, General surgery resident at Bombay Hospital, India.

\section{Received Date: 27 September, 2021 | Accepted Date: 29 October 2021 | Published Date: 05 January 2022}

Citation: Prathamesh P, Raviraj C, Chatterjee S. (2022). Curious case of Retrosternal Colloid Goitre. Journal of Clinical Surgery and Research. 3(1); DOI: 10.31579/2768-2757/032

Copyright: (92022 Chatterjee S, This is an open-access article distributed under the terms of the Creative Commons Attribution License, which permits unrestricted use, distribution, and reproduction in any medium, provided the original author and source are credited.

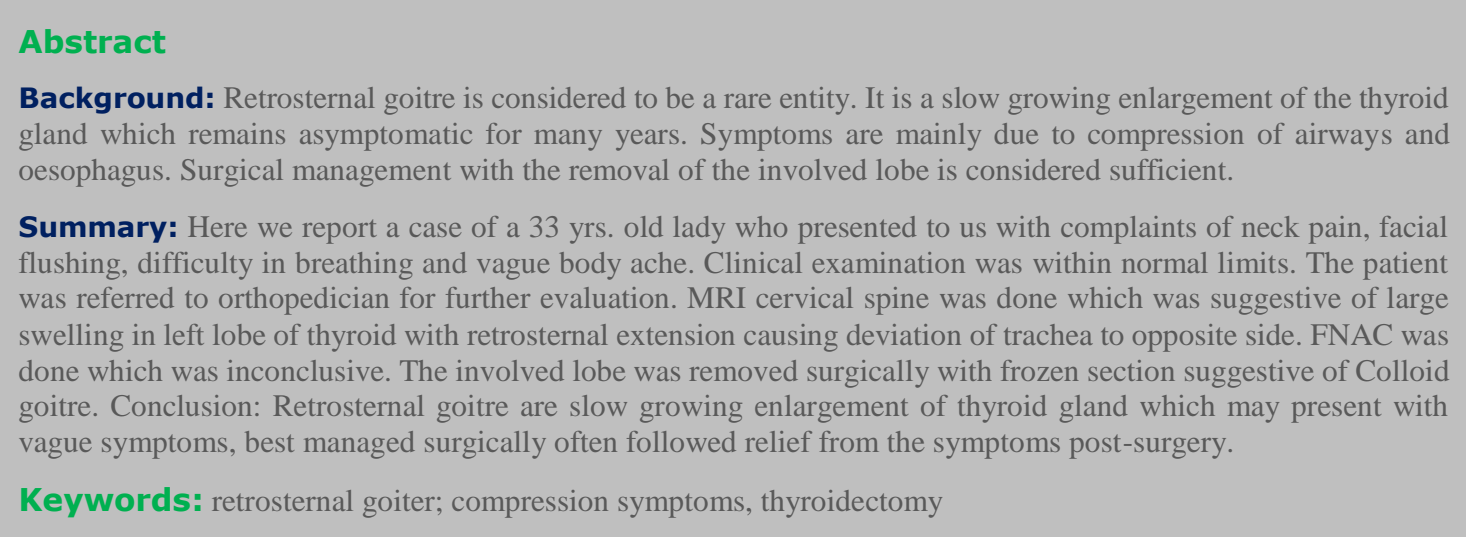

\section{Introduction}

Goitre is defined as any swelling in the neck resulting from enlargement of thyroid gland. The prevalence of goitre is attributed to multiple factors and is around $15.8 \%$ worldwide [1]. in India, it is estimated that 54 million people are suffering from goiter [2]. Retrosternal goitre amongst all the goiters is considered to be a rare entity. Ametanalysis showed a prevalence of approx. $6.28 \%$ of all the cases of goiter [3]. Retrosternal goitre is defined as a goitre i.e. enlargement of thyroid gland with $>50 \%$ located in the mediastinum. The natural history of retrosternal goitre is suggestive of a slow growing enlargement of the gland with patient being asymptomatic for many years. Most of the retrosternal goitres are detected incidentally on radiological examination. The most common symptoms of retrosternal goitre are associated with compression of the airways and esophagus $[4,5]$. Excision of the goitre with hemi- thyroidectomy of the involved lobe is considered sufficient for retrosternal goitre. Cervical approach is considered sufficient for the excision of the retrosternal goitre. Very rarely, full sternotomy or manubriotomy or thoracotomy is reportedly required for the excision of the retrosternal goitre. Here we present a case of one such retrosternal goitre and its course of management.

\section{Case Report}

A 33 yrs old female with no known comorbidities came to the OPD with complaints of neck pain, facial flushing, difficulty in breathing in lying down position and vague bodyache since 15 days. No h/o fever, difficulty in swallowing, change ofvoice, swelling in the neck was identified. There was no past surgical or significant medical history. No history of consumption of any regular medication or drug allergies were identified. Clinical examination was completely within normal limits.

The patient was referred to orthopedician for further evaluation. MRI of the cervicalspine with screening whole spine was adviced with some blood investigations. MRIwas suggestive of a large swelling in the left lobe of thyroid with retrosternal extension causing deviation of trachea to the opposite side and compression effectover the structures in the neck. 


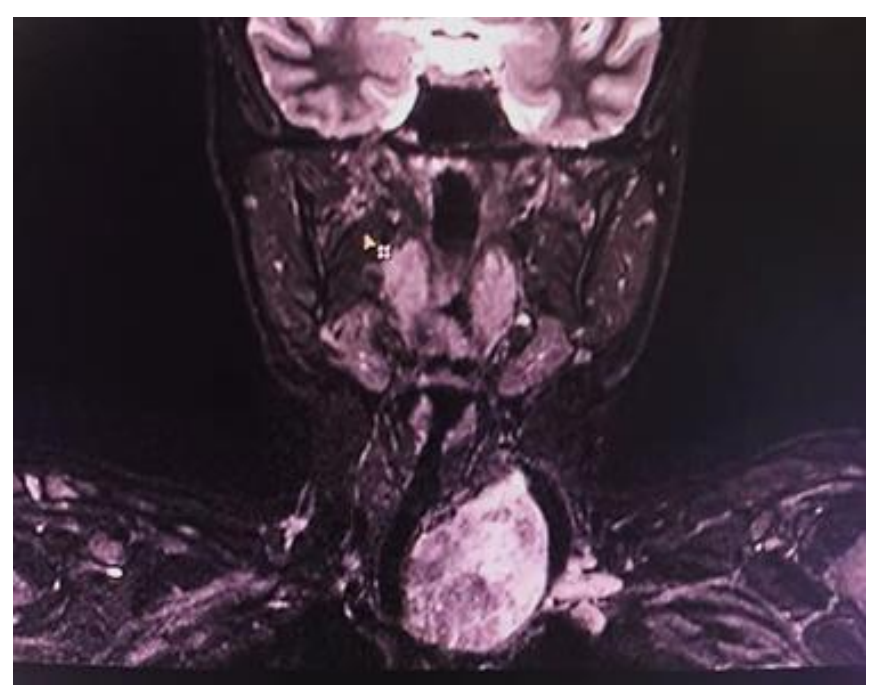

Figure 1: MRI neck showing left thyroid mass with retrosternal extension deviating trachea towards right and causing compressive effects over the structures in the neck.

Blood investigations were send to know the thyroid status. The patient was clinically and biochemically euthyroid. FNAC was done which was inconclusive. The patient was then posted for surgery with intraop frozen section. Intraoperatively a horizontal skin crease incision was taken 4-5 $\mathrm{cm}$ above the suprasternal notch. Incision was deepened. Subplatymal planes were created and flaps were raised. Midline was seen deviated towards the right. Strap muscles were separated accordingly. Left lobe of thyroid enlarged with lower part extending retrosternal. The retrosternal part was delivered out and left hemithyroidectomy was done. The specimen was sent for intraop frozen section. Frozen section was suggestive of colloid goitre. Post-surgery all the symptoms of the patients got relieved.

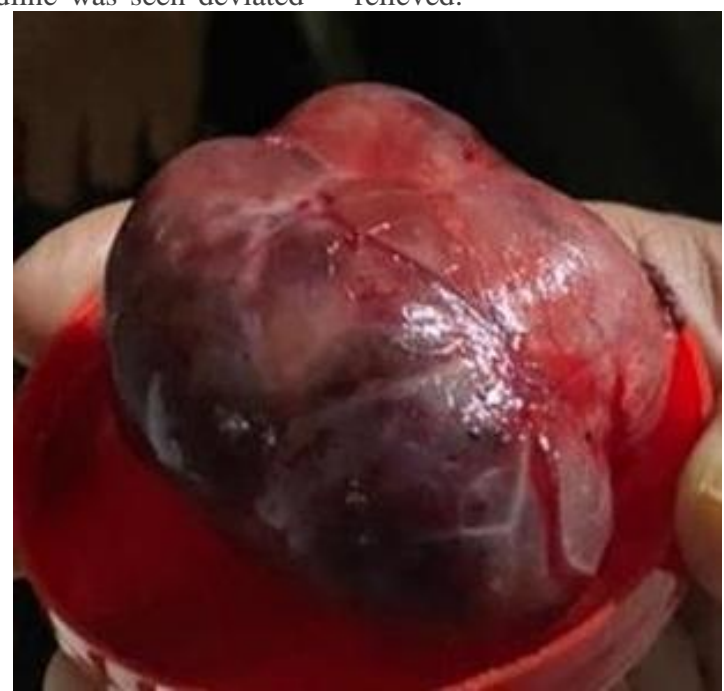

Figure 2: Specimen of left hemi-thyroidectomy with left lobe showing retrosternal extension

\section{Discussion}

Treatment of retrosternal goitre has always been challenging. However, surgical excision remains the gold standard treatment of symptomatic retrosternal goitre. Symptoms of retrosternal goitre are mostly due to compression of the airways and oesophagus. Symptoms include breathlessness due to choking sensation, inability to sleep comfortably, difficulty in swallowing and hoarseness of voice. Less commonly, signs of compression of vessels i.e. superior vena cava syndrome and nerves i.e. Horner's syndrome. There is still a controversy regarding treatment of asymptomatic retrosternal goitres. Traditionally, retrosternal goitre was considered to be the absolute indication for the surgical management. However, there is controversy regarding treatment of asymptomatic retrosternal goitres. The evidence suggests surgical excision of retrosternal goitre at an earliest preventing complications. Retrosternal goitre in majority of the cases can be excised via the cervical approach itself with some patient requiring sternotomy. There are no upfront guidelines which helps a surgeon to pre-operatively anticipate requirement of sternotomy for thesurgical excision of thyroid gland. It had suggested by some studies that presence ofpresence of malignancy, involvement of posterior mediastinum, presence of ectopic thyroid and extension beyond the aortic arch will require midline sternotomy extension of the cervical incision $[3,4,5,6]$.

\section{References}

1. Gebremichael G, Demena M, Egata G, Gebremichael B. (2020). Prevalence of Goiter and Associated Factors Among Adolescents in Gazgibla District, Northeast Ethiopia. Glob Adv Health Med.

2. Reddy T S, Kamath VG, Jacob GP, Kamath A, Rebeiro C. 
(2019). Prevalence of goiter and its association with iodine status among the women of reproductive age group in coastal villages of Udupi Taluk, Karnataka, India. Indian J Public Health. 63:199-202.

3. Charles T. Huins, Christos Georgalas, Homoyoon Mehrzad, Neil S. Tolley. (2008). A new classification system for retrosternal goitre based on a systematic review of its complications and management. International Journal of Surgery. 6(1); 71-76.

4. Abdelrahman H, Al-Thani H, Al-Sulaiti M, Tabeb A, ElMenyar A. (2020). Clinical Presentation and Surgical Treatment of Retrosternal Goiter: A Case Series Study. Qatar Med J. (1):13.

5. Rugiu MG, Piemonte M. (2009). Surgical approach to retrosternal goitre: do we still need sternotomy? Acta Otorhinolaryngol Ital. 29(6):331-338.
6. Hardy RG, Bliss RD, Lennard TW, Balasubramanian SP, Harrison BJ. (2009). Management of retrosternal goitres. Ann R Coll Surg Engl 91(1):8-11.

7. Stafford, N., Youngs, R., Waldron, J., Baer, S., \& Randall, C. (1986). Obstructive sleep apnoea in association with retrosternal goitre and acromegaly. The Journal of Laryngology \& Otology, 100(7); 861-863.

8. Kumar A, Pulle M.V, Asaf B.B. et al. (2021). Retro-sternal Goitre: an Overview. Indian JSurg Oncol.

9. Welman, K., Heyes, R., Dalal, P. et al. (2017). Surgical Treatment of Retrosternal Goitre. Indian J Otolaryngol Head Neck Surg. 69, 345-350.

10. Rugiu MG, Piemonte M. (2009). Surgical approach to retrosternal goitre: do we still need sternotomy?. Acta Otorhinolaryngol Italy. 29(6):331-338.
This work is licensed under Creative Commons Attribution 4.0 License

To Submit Your Article Click Here: Submit Manuscript

DOI: $10.31579 / 2768-2757 / 032$
Ready to submit your research? Choose Auctores and benefit from:

$>$ fast, convenient online submission

$>$ rigorous peer review by experienced research in your field

$>$ rapid publication on acceptance

$>$ authors retain copyrights

$>$ unique DOI for all articles

$>$ immediate, unrestricted online access

At Auctores, research is always in progress.

Learn more auctoresonline.org/journals/journal-of-clinical-surgery-andresearch 